ERICKSEN, Lauro. Representatividade sindical dos domésticos e os limites das negociações coletivas. Revista Eletrônica Direito e Política, Programa de Pós-Graduação Stricto Sensu em Ciência Jurídica da UNIVALI, Itajaí, v.13, n.2, $2^{\circ}$ quadrimestre de 2018. Disponível em: www.univali.br/direitoepolitica - ISSN 1980-7791

\title{
REPRESENTATIVIDADE SINDICAL DOS DOMÉSTICOS E OS LIMITES DAS NEGOCIAÇÕES COLETIVAS
}

\author{
UNION REPRESENTATION OF DOMESTIC EMPLOYERS AND COLLECTIVE \\ BARGAINING LIMITS
}

Lauro Ericksen ${ }^{1}$

SUMÁRIO: Introdução; 1 Sindicalização, representação e legitimidade dos sindicatos dos domésticos; 2 Liame subjetivo e representatividade legal do sindicato dos empregadores domésticos; 3 Possibilidade de limitação do direito fundamental do reconhecimento das negociações coletivas dos empregados domésticos; Considerações finais; Referências das fontes citadas.

\section{RESUMO}

Objetiva, principalmente, perscrutar a questão sindical das empregadas e empregados domésticos após a emenda constitucional no 72, a qual criou uma miríade de novos direitos para esses empregados. A metodologia utilizada consiste em promover uma análise conceitual das categorias econômica e profissional desse setor para poder compreender as peculiaridades do trabalho doméstico e de sua sindicalização. Os resultados obtidos apontam para a contradição existente entre a obrigatoriedade das negociações coletivas a serem engendradas entre as respectivas categorias domésticas, dada a impossibilidade fática de liame subjetivo entre os integrantes da categoria econômica. Conclui que a emenda em relevo cria um problema prático para a sindicalização destas empregadas e destes empregados, gerando uma confusa situação jurídica no plano do direito coletivo do trabalho.

Palavras-chave: Direito Constitucional; Direito Coletivo do Trabalho; Sindicatos; Empregados Domésticos; Negociação Coletiva.

\section{ABSTRACT}

It studies the housekeepers union issues developed after the constitutional amendment $n^{\circ}$ 72, which one created a whole new law system to them. The methodology employed consists on the analysis of the economic and professional categories concept, comprehending the idiosyncrasy of domestic work and its syndicalism. The results indicate that there is contradiction between the obligatory collective negotiation and the factual impossibility to engender a

${ }^{1}$ ERICKSEN, Lauro. Doutor (2016 - UFRN), mestre (2012 - UFRN) e Bacharel em Filosofia (2015 - UFRN). Bacharel em Direito (2008 - UFRN), Especialista em Direito e Processo do Trabalho (UCAM - 2011). Oficial de Justiça do Tribunal Regional do Trabalho da 21a Região (Rio Grande do Norte), lotado na Vara do Trabalho de Macau, RN, Brasil. lauroericksen@yahoo.com.br http://lattes.cnpq.br/8447713849678899 
ERICKSEN, Lauro. Representatividade sindical dos domésticos e os limites das negociações coletivas. Revista Eletrônica Direito e Política, Programa de Pós-Graduação Stricto Sensu em Ciência Jurídica da UNIVALI, Itajaí, v.13, n.2, 20 quadrimestre de 2018. Disponível em: www.univali.br/direitoepolitica - ISSN 1980-7791

subjective bond among economical category members, due to domestic works own nature. Concludes that the mentioned amendment creates a major and practical union issue, making the new system of labor law for the housekeepers something confuse and contradictory.

Keywords: Constitutional Law; Collective Labor Law; Unions; Housekeepers; Collective Bargaining.

\section{INTRODUÇÃO}

O presente trabalho tem como seu fundamento as inovações trazidas ao ordenamento jurídico brasileiro pela Emenda Constitucional no 72, de 02 de abril de 2013. Esta Emenda trata da alteração da redação do parágrafo único do art. 70 da Constituição da República para "estabelecer a igualdade de direitos trabalhistas entre os trabalhadores domésticos e demais trabalhadores urbanos e rurais", segundo menciona a sua própria ementa.

A redação da Emenda em relevo é bastante concisa e propõe a alteração do parágrafo único do mencionado artigo 70, o qual passou a ter a seguinte redação: "O parágrafo único do art. 70 da Constituição Federal passa a vigorar com a seguinte redação: 'São assegurados à categoria dos trabalhadores domésticos os direitos previstos nos incisos IV, VI, VII, VIII, X, XIII, XV, XVI, XVII, XVIII, XIX, XXI, XXII, XXIV, XXVI, XXX, XXXI e XXXIII e, atendidas as condições estabelecidas em lei e observada a simplificação do cumprimento das obrigações tributárias, principais e acessórias, decorrentes da relação de trabalho e suas peculiaridades, os previstos nos incisos I, II, III, IX, XII, XXV e XXVIII, bem como a sua integração à previdência social'". Ainda que vários destes pontos sejam deveras complicados, no que tange a sua aplicabilidade prática, o artigo em tela tem como de fulcro apenas a alteração lançada sobre o inciso XXVI do referido artigo.

O inciso mencionado diz respeito ao "reconhecimento das convenções e acordos coletivos de trabalho". Assim sendo, a partir da entrada em vigor da nova emenda constitucional, e consequente alteração de seu texto, tem-se que serão reputados válidos para todos os fins de direito as convenções e acordos coletivos (negociações coletivas) que venham a ser celebrados entre os sindicatos das trabalhadoras e dos trabalhadores domésticos e dos empregadores domésticos. 
ERICKSEN, Lauro. Representatividade sindical dos domésticos e os limites das negociações coletivas. Revista Eletrônica Direito e Política, Programa de Pós-Graduação Stricto Sensu em Ciência Jurídica da UNIVALI, Itajaí, v.13, n.2, 20 quadrimestre de 2018. Disponível em: www.univali.br/direitoepolitica - ISSN 1980-7791

Todavia, é aí que surge o problema, como é possível que haja uma representação sindical adequada das empregadas e dos empregadores domésticos?

É sobre essa temática que o trabalho pretende se dedicar a analisar, perscrutando os conceitos elementares da representação sindical e da condição laboral da empregada e do empregado doméstico sob a premissa básica da análise constitucional da alteração proposta pela EC 72/2013. Erigindo, como problemática essencial dessa discussão a questão prática da viabilidade econômica e política da instituição de sindicatos organizados pelos empregadores para poder viabilizar as negociações e acordos coletivos entre as categorias envolvidas, pesquisando, assim, até que ponto é limitável.

Há de ser colocado que o objetivo geral do trabalho em curso se atém a analisar as implicações constitucionais ocasionadas pela EC 72 na questão da representação sindical brasileira. De modo amplo, o trabalho consiste em discutir os limites constitucionais da representatividade e da legitimidade sindical, principalmente no que diz respeito à organização sindical da classe empregadora, erigindo a questão prática de tal problemática como objetivo primevo a ser perscrutado no presente trabalho. Ou seja, é possível haver uma união de interesses econômicos entre os empregadores domésticos no que diz respeito a uma colusão classista propriamente dita, tal como dita as normas do Direito coletivo do trabalho?

Os objetivos específicos do trabalho em relevo consistem em discorrer sobre as inovações legislativas trazidas pela EC 72, mais especificamente no que ela enuncia sobre as negociações coletivas; analisar a representatividade e a legitimação sindical após essas mudanças; verificar até que ponto o componente econômico, inexistente nas relações de trabalho domésticas, é importante na representatividade sindical; observar se os novos regramentos constitucionais do trabalho doméstico não ferem pressupostos democráticos na imposição de uma conflagração sindical politicamente organizada; e, por fim, formular implicações jurídicas acerca do descompasso constitucional da instauração de uma necessidade de se haver a formação de sindicatos das empregadas e dos 
ERICKSEN, Lauro. Representatividade sindical dos domésticos e os limites das negociações coletivas. Revista Eletrônica Direito e Política, Programa de Pós-Graduação Stricto Sensu em Ciência Jurídica da UNIVALI, Itajaí, v.13, n.2, 20 quadrimestre de 2018. Disponível em: www.univali.br/direitoepolitica - ISSN 1980-7791

empregadores domésticos, em virtude da impossibilidade fática para tal organização, defendendo, portanto, a limitação de tal direito constitucional em face da impossibilidade fática de organização sindical dos empregadores.

Nesse passo, é importante explicar melhor a metodologia empregada no presente trabalho. Adota-se como marco teórico a Teoria Geral dos Sistemas, mais especificamente o seu pensamento sistemático acerca da proibição do excesso aplicado às inovações trazidas à Constituição da República de 1988 por meio da EC 72. A coleta e absorção de informações consistem na pesquisa dentre as diversas fontes do Direito, notadamente legislação, doutrina e jurisprudência, aplicadas à análise crítica da realidade constitucional no tocante ao tema proposto, com aplicação do método hipotético-dedutivo. O cerne da pesquisa repousa nas disposições constitucionais acerca da possibilidade de negociações (acordos e convenções) coletivas para os empregados domésticos, revelando um grande interesse social envolvido.

\section{SINDICALIZAÇÃO, REPRESENTAÇÃo E LEGITIMIDADE DOS SINDICATOS DOS DOMÉSTICOS}

Inicialmente, há de se abrir o presente tópico explanando que o seu escopo mais esforçado consiste em conglobar, em uma única pontuação, desde a questão da problemática até os pormenores do referencial teórico que envolve a questão da representação e legitimidade da sindicalização da categoria profissional dos domésticos, sob o viés de sua limitação constitucional. Assim, o tópico em tela além de tratar do problema envolvido nessa seara, cuida também do tema escolhido, da hipótese de trabalho e do aprofundamento teórico da questão a ser debatida, sendo esse o composto mais amplo daquilo que pode justificar a própria necessidade de tal contexto ser perscrutado mais detidamente no trabalho por ora em curso.

É importante iniciar a presente análise assentando que ela tematiza, precipuamente, os direitos e garantias fundamentais de organização social em torno dos direitos sociais dos trabalhadores, tal como estatuídos em alguns dos incisos dos artigos $5^{\circ}$ e 70 da Constituição da República de 1988 (os quais serão mais bem detalhados mais adiante). Existe, portanto, um direito de "constituir 
ERICKSEN, Lauro. Representatividade sindical dos domésticos e os limites das negociações coletivas. Revista Eletrônica Direito e Política, Programa de Pós-Graduação Stricto Sensu em Ciência Jurídica da UNIVALI, Itajaí, v.13, n.2, 20 quadrimestre de 2018. Disponível em: www.univali.br/direitoepolitica - ISSN 1980-7791

organizações de sua escolha", traduzindo-se na possibilidade de os trabalhadores e, consequentemente, dos empregadores, também, de formar um sindicato, com a estrutura e a representatividade que considerem mais convenientes; essa é a expressão máxima que o direito fundamental de organização laboral pode atingir para Arnaldo Süßekind ${ }^{2}$. O direito de se constituir uma organização, que orbite em torno dos próprios interesses, é algo inalienável, é um direito fundamental de cada cidadão em seu espectro laboral e produtivo, isso porque, a mencionada organização, versará, em maior ou menor medida, sobre seus interesses laborais como um todo coletivo, no qual, seus anseios, desejos e percalços serão discutidos por aqueles que porventura se filiem a tal ente coletivo.

Não obstante, há de se destacar, na trilha introdutória do que foi anteriormente colocado, que, para a classe obreira, é deveras fácil que haja uma organização sindical para defender os seus interesses mais próprios e para lutar para as melhorias de suas condições de vida e de trabalho. No entanto, o direito coletivo do trabalho (o sub-ramo legal para qual a norma constitucional irradia os seus efeitos) é um segmento do Direito que, ao contrário do direito material do trabalho, por exemplo, lida com entes coletivos postos em plenas igualdades de condição em suas tratativas. Segundo Américo Plá Rodriguez ${ }^{3}$, o princípio da igualdade entre os entes sindicais no direito coletivo do trabalho rompe com a lógica do direito individual do trabalho, todo construído em torno da defesa do hipossuficiente. É necessário ter a noção que esse rompimento com o tratamento desigual aos desiguais, para se rememorar o célebre adágio aristotélico, não tem o escopo de ser uma mera inversão de ordem em termos de análise ou de contraposição entre o direito individual e o coletivo do trabalho. Tal reversão é imprescindível para que não se crie uma distorção mais desigual (no âmbito coletivo) que a própria desigualdade existente no campo individual.

Repetir a mesma formulação "não igualitária" dos modelos individuais trabalhistas acabaria por trazer um profundo desequilíbrio entre os entes

\footnotetext{
2 SÜßEKIND, Arnaldo Lopes. Direito Constitucional do Trabalho. 3. ed. São Paulo: Renovar, 2004, p. 368.

3 RODRIgueZ, Américo Plá. Princípios de Direito do Trabalho. 3. ed. Tradução de Wagner D. Giglio. São Paulo: LTr, 2000, p. 28.
} 
ERICKSEN, Lauro. Representatividade sindical dos domésticos e os limites das negociações coletivas. Revista Eletrônica Direito e Política, Programa de Pós-Graduação Stricto Sensu em Ciência Jurídica da UNIVALI, Itajaí, v.13, n.2, 20 quadrimestre de 2018. Disponível em: www.univali.br/direitoepolitica - ISSN 1980-7791

coletivos, pois haveria de beneficiar, exclusivamente o ente coletivo profissional, o qual, em sua união de forças individuais, compreendido unitariamente, tem o mesmo poder de negociação e de discussão que qualquer outro ente coletivo, seja ele o sindicato da categoria econômica, ou, até mesmo o Estado, em sua consideração hegeliana de ente coletivo por excelência. Por causa dessa cessação da hipossuficiência não se pode, em momento algum, ao se falar de entes sindicais, questionar se há algum polo a ser, de antemão, beneficiado por alguma forma de proteção em termos específicos de diferença de forças de estabelecimento, seja esse estabelecimento no plano fático da atuação do dia a dia de suas obrigações coletivistas, ou, até mesmo, no âmbito jurídico da paridade de armas em termos de negociações e acordos de trabalho para as categorias envolvidas (sendo essa temática a mais importante para o trabalho em desenvolvimento).

Assim, as diferenças classistas, entre empregadores e empregados, existentes nas relações individuais entre eles encetadas, não existem quando eles são representados em suas respectivas coletividades (entes que se organizam coletivamente, como os sindicatos representantes das classes). Não obstante, os sindicatos, tanto de uns representados quanto de outros, são tidos como ocupantes do mesmo patamar jurídico quando negociam acordos e convenções de trabalho válidas para toda a categoria econômica.

O conceito de categoria econômica (também chamada de categoria dos empregadores) é dado no artigo 511, parágrafo $1^{0}$ da $\mathrm{CLT}^{4}$, e ocorre quando há solidariedade de interesses econômicos dos que empreendem atividades idênticas, conexas ou similares, esse conceito usado pela lei brasileira foi delineado por Gino Giugni ${ }^{5}$ ao tratar do direito sindical italiano, em um dos seus escritos clássicos sobre o tema. Afinal, este é o "vínculo social básico" a agregar os componentes da categoria econômica. Nesse passo, por vínculo social básico

\footnotetext{
${ }^{4}$ Nesse sentido se posiciona a jurisprudência do Tribunal Regional do Trabalho da 2a Região: Ação de Cumprimento. Sindicato. Enquadramento Sindical. $\mathbf{O}$ correto enquadramento sindical decorre da representatividade fixada pelo $\$ 10$, do art. 511, da CLT, através da "solidariedade de interesses econômicos", e não em razão da conveniência do interessado. Recurso que se nega provimento. Acórdão no: 20130301048. Juiz Relator: Rui César Publio Borges Correia Turma: 18 Data da publicação: 05-04-2013.
}

${ }^{5}$ GIUGNI, Gino. Diritto Sindacale. Bari: Cacucci, 2010, p. 54. 
ERICKSEN, Lauro. Representatividade sindical dos domésticos e os limites das negociações coletivas. Revista Eletrônica Direito e Política, Programa de Pós-Graduação Stricto Sensu em Ciência Jurídica da UNIVALI, Itajaí, v.13, n.2, 20 quadrimestre de 2018. Disponível em: www.univali.br/direitoepolitica - ISSN 1980-7791

se deve compreender o liame existencial mais elementar a congregar os indivíduos em torno de uma questão cotidiana que Ihes é comum, ou seja, o trabalho faz com que sua relação social mais comezinha seja estatuída em torno desse cotidiano repartido e compartilhado diuturnamente. É, portanto, ao orbitar a esfera do labor e da cotidianidade que o mencionado vínculo social básico se estabelece e se perpetua para além da mera existência fática dos indivíduos, repercutindo, em grande monta, na esfera jurídica de suas interações sociais também.

Não obstante, por mais que se tente enquadrar o sindicato dos empregadores domésticos no termo "similar" - ou "ramos que se parecem" em sua atividade preponderante - com outras atividades, há de se ter em conta que não há nenhuma similaridade nem entre os próprios empregadores dessa mesma atividade, quiçá com os demais empregadores de outras atividades similares (como, por exemplo, a dos auxiliares de serviços gerais, ou de limpeza e manutenção). Ademais, nessa toada, há de se advertir que, se o próprio sindicalismo (em seus atos irregulares e ilegais, como ocorre na prática) pode ser danoso para o bem estar econômico dentro do contexto jurídico do direito do trabalho ${ }^{6}$, ele pode ainda ser mais perigoso quando, com respaldo constitucional, é capaz de ferir a igualdade dos entes coletivos (supostamente) envolvidos nas negociações laborais. Até porque, a própria doutrina ${ }^{7}$, historicamente, ao tratar do tema, sempre previu a negociação coletiva como sendo algo feito entre representantes sindicais de empresas privadas ou, no máximo, representando o Estado e os órgãos de sua administração direta, indireta ou fundacional, mas, nunca em referência aos empregadores pessoa física (ou família).

É com esse fulcro que se chega, precipuamente, à questão da representatividade dos entes sindicais, um instituto que, como já aludido anteriormente, findará por repercutir de maneira sensível em uma miríade de outros institutos anexos. Há de se salientar que o termo representatividade é diferente de representação

6 FREEMAN, Richard B.; MEDOFF, L. James. What do Unions Do? New York: Basic Books, 1984, p. 190.

7 COSTA, Orlando Teixeira da. Direito Coletivo do Trabalho e Crise Econômica. São Paulo. LTr, 1991, p. 134. 
ERICKSEN, Lauro. Representatividade sindical dos domésticos e os limites das negociações coletivas. Revista Eletrônica Direito e Política, Programa de Pós-Graduação Stricto Sensu em Ciência Jurídica da UNIVALI, Itajaí, v.13, n.2, 20 quadrimestre de 2018. Disponível em: www.univali.br/direitoepolitica - ISSN 1980-7791

sindical, como bem alude Amauri Mascaro Nascimento ${ }^{8}$. A representatividade possui um conteúdo político bastante delineado e é extraída dos indicadores sociais e fáticos, ainda que indiretos, que retratam o grau de aceitação daquela entidade pelos seus representados em face do outro polo (critério do mútuo reconhecimento). Nesse passo, como bem destaca Henrique Macedo Hinz ${ }^{9}$, é a representação legal dos entes coletivizados que faz com que haja a aplicação automática e involuntária dos instrumentos normativos gerados nos processos coletivos de negociação (acordos e convenções) ${ }^{10}$, algo depreendido da exegese do artigo 513, alínea "a", do texto celetista. Ou seja, o que for decidido em sede de atuação coletiva sindical há de ser aplicado independentemente da anuência individual de cada empregador, por isso que a sua representação legal em tais tratativas de pactos coletivos é importante, aliás, imprescindível. Não há como sequer se imaginar o direito coletivo do trabalho sem que as normas negociadas (ou acordadas) sejam imediatamente inseridas nos contratos de trabalho vigentes, pois, caso fosse necessário uma nova rodada discussão acerca dos direitos insertos nos conteúdos de tais tratativas não haveria o mínimo de efetividade em tais instrumentos coletivos.

A representação sindical se dá em duas esferas: no âmbito coletivo (ou âmbito geral) e no âmbito individual ${ }^{11}$. Na sua vertente coletiva, o sindicato trata dos interesses gerais da categoria representada, lembrando sempre que tais interesses são definidos em função da sua relação com a categoria oposta, ao Estado ou a certos órgãos privados (entes do terceiro setor e cooperativas). Deste modo, o sindicato é o intérprete das aspirações ou posições daqueles que fazem parte da categoria que lhe é fundante. No que tange à representação individual, o sindicato tem como tarefas práticas a homologação de rescisões e resoluções contratuais, a participação em medidas judiciais, dentre outros

8 NASCIMENTO, Amauri Mascaro. Curso de Direito do Trabalho: História e Teoria Geral do Direito do Trabalho/Relações Individuais e Coletivas do Trabalho. 25. ed. São Paulo: Saraiva, 2010, p. 1267.

9 HINZ, Henrique Macedo. Direito Coletivo do Trabalho. São Paulo: Saraiva, 2012, p. 30.

10 Nesse sentido: "[...] não há como obrigar a reclamada ao cumprimento de normas das quais não participou através de Sindicato próprio". Recurso de Revista - 485511-49.1998.5.15.5555 Data de Julgamento: 02/05/2001, Relator Juiz Convocado: Carlos Francisco Berardo, $3^{a}$ Turma, Data de Publicação: DJ 24/05/2001.

${ }^{11}$ HINZ, Henrique Macedo. Direito Coletivo do Trabalho. São Paulo: Saraiva, 2012, p. 31. 
ERICKSEN, Lauro. Representatividade sindical dos domésticos e os limites das negociações coletivas. Revista Eletrônica Direito e Política, Programa de Pós-Graduação Stricto Sensu em Ciência Jurídica da UNIVALI, Itajaí, v.13, n.2, 20 quadrimestre de 2018. Disponível em: www.univali.br/direitoepolitica - ISSN 1980-7791

expedientes burocráticos de menor interesse para o presente trabalho, para o qual a dimensão coletiva é mais importante.

\section{LIAME SUBJETIVO E REPRESENTATIVIDADE LEGAL DO SINDICATO DOS EMPREGADORES DOMÉSTICOS}

Levando em conta as designações teóricas pretéritas é fácil perceber o problema prático que surge dessa inovação constitucional: a partir dessa alteração os sindicatos dos empregados domésticos - organizações de natureza jurídica particular, que ainda assim, possuem interesses públicos evidentes em suas reivindicações ${ }^{12}$ - poderão negociar novos direitos e novas garantias de trabalho para toda a categoria com os sindicatos dos empregadores domésticos. Mas, o problema é justamente este: não existe uma organização sindical dos empregadores domésticos, justamente porque não há um liame representativo entre esses empregadores.

Não há como se fugir da definição de sindicato como sendo uma confluência de interesses coletivizados em prol de um objetivo econômico bem delimitado ${ }^{1314}$. Deste núcleo duro básico é que se desdobram todas as demais prerrogativas sindicais, como participação em negociações e acordos, autonomia sindical, representação e filiação sindicais, dentre outras ${ }^{15}$. De maneira ainda mais acurada, José Augusto Rodrigues Pinto ${ }^{16}$ pontua que a expectativa existente é que o sindicato seja capaz de dar uma sólida contribuição para o robustecimento do "espírito conciliador de interesses entre capital e trabalho cujo estuário natural será sempre a negociação coletiva". Assim sendo, há de se perceber que a negociação possui um elemento dual bastante exposto, já que se necessita conciliar vontades opostas, a representação de tais vontades, tanto no plano

\footnotetext{
12 CHIARELLI, Carlos Alberto. O Trabalho e o Sindicato: Evoluções e Desafio. São Paulo, LTr, 2005, p. 222.

13 BATALHA, Wilson de Souza Campos. Sindicatos, Sindicalismo. 2. ed. São Paulo: LTr, 1994, p. 36.

14 NASCIMENTO, Amauri Mascaro. Direito Sindical. 2. ed. São Paulo: Saraiva, 2001, p. 136.

15 RUSSOMANO, Mozart Victor. Princípios Gerais de Direito Sindical. 2. ed., Rio de Janeiro: Forense, 1995, p. 65.

16 PINTO, José Augusto Rodrigues. Direito Sindical e Coletivo do Trabalho. 2. ed. São Paulo: LTr, 2002, p. 195.
} 
ERICKSEN, Lauro. Representatividade sindical dos domésticos e os limites das negociações coletivas. Revista Eletrônica Direito e Política, Programa de Pós-Graduação Stricto Sensu em Ciência Jurídica da UNIVALI, Itajaí, v.13, n.2, 20 quadrimestre de 2018. Disponível em: www.univali.br/direitoepolitica - ISSN 1980-7791

político quanto econômico deverá ocorrer em plena igualdade por ambos os entes coletivos envolvidos nessa dinâmica social. Neste horizonte, de maneira bastante lúcida, Vólia Bonfim Cassar $^{17}$ ao tratar deste tema, erige a igualdade dos entes laborais ao patamar de princípio, o qual ela denomina de "princípio da equivalência entre os negociantes". Ela vai além e distingue que a equivalência se dá entre os sindicatos (obreiro e dos empregadores) e não entre os membros da categoria, uma vez que os sindicatos têm a mesma equivalência jurídica e econômica com igualdade jurídica para negociarem. Assim, por mais que existam diferenças e vontades contraditórias entre os membros de uma mesma categoria, todas as desavenças são dissipadas pela emissão da vontade do ente coletivo, o qual finda por vincular, obrigatoriamente, em suas negociações, toda a categoria, mesmo que parte dela discorde do que for acertado como válido por meio dos instrumentos coletivos de negociação.

O que importa destacar de todo esse bojo jurídico é que não há, no plano fático, nenhum liame existente entre os empregadores domésticos que venha a justificar a sua confluência de interesses, não há nenhuma repartição em comum de objetivos a serem postos em pauta por tais empregadores, dito de maneira mais clara: em virtude de não haver lucro na atividade doméstica, não há um elemento econômico comum aos "exploradores dessa atividade". Nunca houve nenhuma ligação entre eles, e qualquer uma que venha a surgir, após a edição da mencionada EC é apenas uma artificialidade, haja vista que não há nenhum interesse econômico que justifique a ligação entre tais empregadores, dada a sua própria diversidade de atuação.

A inovação trazida pela mencionada EC finda por ser contraditória com o princípio da intervenção obrigatória dos sindicatos, contido nos incisos III e VI do artigo $8^{\circ}$ da Constituição da República de 1988 e no artigo 611 da CLT. As raras exceções a esse princípio se dão quando não há sindicato na categoria econômica e quando há a recusa para a negociação coletiva ${ }^{18}$, todavia, o caso em análise não se enquadra em nenhum dos casos. Não se enquadra na primeira

\footnotetext{
17 CASSAR, Vólia Bonfim. Direito do Trabalho. 7. ed. São Paulo: Método, 2012, p. 1209.

18 CASSAR, Vólia Bonfim. Direito do Trabalho. 7. ed. São Paulo: Método, 2012, p. 1210.
} 
ERICKSEN, Lauro. Representatividade sindical dos domésticos e os limites das negociações coletivas. Revista Eletrônica Direito e Política, Programa de Pós-Graduação Stricto Sensu em Ciência Jurídica da UNIVALI, Itajaí, v.13, n.2, 20 quadrimestre de 2018. Disponível em: www.univali.br/direitoepolitica - ISSN 1980-7791

hipótese porque a negociação direta por ausência sindical haveria por ocasionar o desequilíbrio entre o empregador doméstico (pessoa natural ou família) em face de um ente coletivo (sindicato dos domésticos), de modo que a ausência sindical dos empregadores não é por mera desorganização ou desmantelamento classista, sendo deveras injusta a imposição da negociação direta. Ademais, por nem sequer haver possibilidade fática de formação do sindicato dos empregadores, a segunda hipótese também há de ser descartada.

Muitos empregadores ocupam funções profissionais das mais diversas, podem ser profissionais liberais (médicos, advogados, empresários), podem ser funcionários públicos, podem ser aposentados, enfim, não há nenhum direcionamento acerca de suas atividades econômicas (ou a origem de tais atividades) que indique um interesse comum a ser partilhado. Isso sem se falar no problema da contribuição sindical (obrigatória) também para os empregadores, haja vista que o fato gerador se subsume apenas ao sujeito passivo estar participando de determinada categoria sindical ${ }^{19}$, com amparo constitucional no artigo 149, caput e parágrafo único, e na CLT no artigo 605. Tal problema diz respeito tanto à cobrança de tal encargo, e também ao espectro de arrecadação de tais valores, o que, sensivelmente, ultrapassa os limites da organização de um sindicato de empregadores sem nenhuma vinculação entre si. Por mais que o direito de associação sindical seja derivado da Declaração Universal dos Direitos do Homem, como bem salienta José de Segadas Vianna ${ }^{20}$, ela deve ser livre e despida de qualquer pressão externa, não pode nem ser advinda da lei ou da própria Constituição, pois isso feriria a liberdade de querer se associar ou não, algo que vem a repercutir, imensamente, na imperiosa necessidade de associação e organização sindical imposta aos empregadores domésticos (pessoas físicas ou entidades familiares).

Aliás, há de se questionar, também, se a própria atividade exercida pelos empregados domésticos, além da retribuição salarial que ela gera, pode ser compreendida como sendo uma atividade eminentemente econômica.

\footnotetext{
19 CATARINO, José Martins. Tratado Elementar de Direito Sindical. São Paulo: LTr, 1977, p. 312.

20 VIANNA, José de Segadas. Direito Coletivo do Trabalho. 2. ed. São Paulo: LTr, 1972, p. 56.
} 
ERICKSEN, Lauro. Representatividade sindical dos domésticos e os limites das negociações coletivas. Revista Eletrônica Direito e Política, Programa de Pós-Graduação Stricto Sensu em Ciência Jurídica da UNIVALI, Itajaí, v.13, n.2, 20 quadrimestre de 2018. Disponível em: www.univali.br/direitoepolitica - ISSN 1980-7791

Esse questionamento é deveras importante, uma vez que, a premissa básica da atividade doméstica consiste em não haver a geração de lucros - o próprio artigo 10, da Lei no 5.859 de 1972 (a qual dispõe sobre a profissão de empregado doméstico), fala de "finalidade não lucrativa" ao se referir à atividade desempenhada pelo empregado doméstico. Há de se distinguir, como o faz Cláudia Cavalcante Normando ${ }^{21}$, entre o trabalho voluntário e 0 trabalho doméstico, pois, ainda que em nenhum dos dois o lucro seja visado, a atividade doméstica não pode ser considerada uma atividade produtiva no sentido capitalista, muito embora, seja desenvolvida em prol de uma pessoa física ou unidade familiar, ao passo que o trabalho voluntário se destina a fins morais em entidades coletivas (ONG's e entidades do terceiro setor em geral, públicas ou privadas). Daí a se depreender que se não há atividade lucrativa no trabalho doméstico, obviamente, não se seria possível o vislumbre de se haver algum interesse em na coletivização dos esforços de tal classe empregadora.

O próprio conceito de empregado doméstico, trazido da doutrina italiana ${ }^{22}$ se atém àquele que tem por objeto as prestações inerentes ao funcionamento da família. Pode, entretanto, referir-se também, não à família, segundo o seu conceito jurídico propriamente dito, senão à tarefa que um trabalhador executa à semelhança do que se realiza entre as paredes domésticas, ao serviço de uma família. De toda forma, essa maneira de realização laboral sempre está atrelada a um ambiente diverso daquele em que se dá a produção econômica trivial, daí as suas peculiaridades genéticas. No mesmo sentido se posiciona Antônio Ferreira Cesarino Júnior ${ }^{23}$, pugnando pela garantia de extensões de direitos sociais aos empregados domésticos, embora sempre ponderando as suas peculiaridades, adaptando-se assim à natureza do trabalho por eles desempenhado, isto é, reconhecendo as suas diferenças essenciais para com os demais empregados (celetistas). Dentre as ventiladas peculiaridades, Rodolfo

21 NORMANDO, Cláudia Cavalcante. Trabalho Doméstico: Valores Jurídicos e Dignidade Humana. São Paulo: Sérgio Antonio Fabris, 2005, p. 63.

22 BARASSI, Ludovico. Il Diritto del Lavoro. Milano: Giuffré, 1949, p. 212.

${ }^{23}$ CESARINO JÚNIOR, Antônio Ferreira. Direito Social. São Paulo, LTr, 1980, p. 208. 
ERICKSEN, Lauro. Representatividade sindical dos domésticos e os limites das negociações coletivas. Revista Eletrônica Direito e Política, Programa de Pós-Graduação Stricto Sensu em Ciência Jurídica da UNIVALI, Itajaí, v.13, n.2, 20 quadrimestre de 2018. Disponível em: www.univali.br/direitoepolitica - ISSN 1980-7791

Pamplona Filho e Marco Antônio César Villatore ${ }^{24}$ destacam os laços de afetividade e a confiança mais sólida ${ }^{25}$, algo que não corre nos demais vínculos empregatícios -, o que acarreta um tratamento diferenciado para tais entes laborais.

Há de se denotar que a corrente análise não se assume uma posição contrária à sindicalização dos empregados domésticos, afinal, há até quem entenda que é possível a sindicalização de categorias profissionais autônomas de profissionais liberais, sem que haja, portanto, a correspondente categoria econômica em oposição ${ }^{2627}$. Ou seja, os empregados domésticos possuem a partir da regulamentação da EC 72 todo o direito de se organizarem sindicalmente, haja vista que tal direito decorre do direito constitucional de associação (incisos XVII e XXI do artigo $5^{0}$ do texto constitucional) ${ }^{28}$. Deve-se ter em relevo a noção de liberdade de associação plena, vedada apenas às associações de caráter paramilitar, quais sejam, "as corporações associativas armadas de natureza religiosa, ideológica, patriótica", dentre outras semelhantes ${ }^{29}$. O problema levantado na presente análise não diz respeito aos sindicatos da classe obreira, e, sim, o direcionamento constitucional de se garantir a viabilidade das negociações e dos acordos coletivos a virem a ser por eles realizados (uma questão de paralelismo simétrico, uma decorrência do princípio da igualdade dos entes coletivos laborais). O problema se insere na obrigatoriedade da representação legal dos empregadores, tal como já bastante discutido anteriormente.

24 PAMPLONA FILHO, Rodolfo; VILLATORE, Marco Antônio César. Direito do Trabalho Doméstico. 3. ed. São Paulo, LTr, 2006, p. 27.

25 Nesse compasso, há de se reconhecer certa dimensão sociológica diferenciada para os empregados domésticos.

26 BARROSO, Fábio Túlio. Direito Coletivo do Trabalho. São Paulo: LTr, 2010, p. 118.

27 Também reconhecido "como paralelismo entre as categorias profissional e econômica". Tal como se depreende da jurisprudência trabalhista analisada: Acórdão no: 20130280237. Juiz Relator Marta Casadei Momezzo Turma: 10. Data da publicação: 01-04-2013.

280 entendimento pela possibilidade do registro sindical dos empregados domésticos precede a própria elaboração da EC 72 (outrora PEC 66/2012), como se encontra esposado no seguinte excerto jurisprudencial: Apelação em Mandado de Segurança no 26682.2002.34.00.026682-9/DF. Relator (a): Desembargador Carlos Fernando Mathias. Julgamento: 26/06/2006. Órgão Julgador: Oitava Turma. Publicação: 14/07/2006 DJ p.82.

${ }^{29}$ CHIARELLI, Carlos Alberto. Trabalho na Constituição. São Paulo: LTr, 1990, p. 11. 
ERICKSEN, Lauro. Representatividade sindical dos domésticos e os limites das negociações coletivas. Revista Eletrônica Direito e Política, Programa de Pós-Graduação Stricto Sensu em Ciência Jurídica da UNIVALI, Itajaí, v.13, n.2, 20 quadrimestre de 2018. Disponível em: www.univali.br/direitoepolitica - ISSN 1980-7791

\section{POSSIBILIDADE DE LIMITAÇÃo DO DIREITO FUNDAMENTAL DO RECONHECIMENTO DAS NEGOCIAÇÕES COLETIVAS DOS EMPREGADOS DOMÉSTICOS}

Nesse compasso, há de se entender que o que se pode ser defendido, em termos de uma justificação jurídica para o presente impasse, é uma limitação ao direito fundamental constitucional das empregadas e dos empregados domésticos em terem as suas negociações e acordos coletivos peremptoriamente reconhecidos como prevalentes ${ }^{30}$. No caso em apreço, há de se ter em conta que se trata de uma verdadeira questão de uma proibição de excesso (Übermaßverbote), nos termos do postulado teórico de Georg-Wilhelm Canaris ${ }^{31}$ (1999, p. 45). O excesso a ser vetado no presente caso diz respeito ao excesso constatado no direito de associação dos empregados domésticos quando não há uma, ainda que mínima possibilidade de congregação simétrica por parte dos empregadores dessa categoria laboral, afeiçoando-se a um vetor interventivo na seara privada $^{32}$. Nessa perspectiva, é importante ter em grau máximo de destaque que não se pode utilizar nenhum artifício protecionista em prol das empregadas e dos empregados domésticos na presente análise, sob pena de se gerar uma interpretação que acarreta inoperância do sistema jurídico (laboral) como um todo $^{33}$. Não tomar partido de uma "pressuposta" parte hipossuficiente (algo que não existe no direito coletivo do trabalho, como já bastante debatido em tópico pretérito), é um elemento que não se pode abrir mão na aplicação da proibição do excesso no presente caso.

30 A própria Constituição da República coloca limites à atuação sindical, como, por exemplo, o princípio da unicidade sindical. Por mais que essa limitação específica esteja em desacordo com a Convenção no 87 da Organização Internacional do Trabalho, há de se ter em conta que a limitação em tela não afronta nem à mencionada Convenção e ainda bem como se alinha ao artigo 10 , item 1 , da Convenção no 154 da própria OIT, que fala especificamente em aplicação de sua aplicação aos casos de negociação coletiva que envolvam "atividade econômica", algo não desenvolvido no trabalho doméstico.

31 CANARIS, Claus-Wilhelm. Grundrechte und Privatrecht: Eine Zwischenbilanz; stark erweiterte Fassung des Vortrags Gehalten vor Juristischen Gesellschaft. Berlin: De Gruyter, 1999, p. 45.

32 MELLO, Marcílio Barenco Corrêa de. O Princípio da Proibição do Excesso na Concessão de Medidas Cautelares pelas Cortes de Contas. Revista do TCEMG, v. 84, n. 3, 2012, p. 70.

${ }^{33}$ FISCHER, Douglas. Execução de Pena na Pendência de Recursos Extraordinário e Especial em Face da Interpretação Sistêmica da Constituição. Uma Análise do Princípio da Proporcionalidade: entre a Proibição de Excesso e a Proibição de Proteção Deficiente. Revista Direito Público, v. 6, n. 25, 2009, p. 15. 
ERICKSEN, Lauro. Representatividade sindical dos domésticos e os limites das negociações coletivas. Revista Eletrônica Direito e Política, Programa de Pós-Graduação Stricto Sensu em Ciência Jurídica da UNIVALI, Itajaí, v.13, n.2, 20 quadrimestre de 2018. Disponível em: www.univali.br/direitoepolitica - ISSN 1980-7791

O grande problema que ocorre quando esse excesso de um direito fundamental não é extirpado do ordenamento jurídico (principalmente do espectro constitucional desse ordenamento) consiste no fato de que o "pretenso direito" finda por se tornar uma fonte de injustiças e distorções sociais, por mais que seja operado em prol de um grupo que tanto espera por mais direitos sociais. Principalmente por causa do desequilíbrio econômico que este excesso pode acarretar, e, em um futuro mais distante, quiçá até mesmo o desaparecimento da classe laboral, dada a falta de procura por tais serviços, é imperioso que ele seja proibido, no sentido de restringir a sua atuação na órbita constitucional.

O "excesso de um direito social dos trabalhadores" não pode ser mantido ou justificado pelo simples fato de, no plano individual, ser mais do que dominante o princípio da proteção laboral (com todas as suas decorrências em favor dos hipossuficientes), recorrer a essa argumentação não é apenas uma falácia lógica calcada em um falso perigo iminente - falácia denominada tecnicamente como "straw man fallacy" nos domínios da lógica filosófica ${ }^{34}$-, e, sim, uma verdadeira "falácia jurídica", pois retoma, indevidamente, como se fosse verdadeiro o modelo de interpretação dos direitos individuais trabalhistas transpondo-o para analisar os direitos coletivos. Não existe como não conceber o reconhecimento das negociações coletivas da categoria doméstica como sendo algo válido dentro da seara jurídica do direito coletivo do trabalho sem que se recorra a esse estratagema interpretativo ominoso. Uma vez que, não existe outras maneiras possíveis de se interpretar essa inovação constitucional que não redundem na mencionada dicotomia da aplicação ou não da hipossuficiência laboral.

Assim por mais que haja uma obrigação estatal de tomar todas as providências necessárias para a realização ou concretização dos direitos fundamentais (no caso, a ampliação do leque dos direitos trabalhistas atribuídos aos domésticos através de uma alteração textual da Constituição brasileira) há de se ter em conta que os direitos fundamentais não podem ser considerados apenas como proibições de intervenção (Eingriffsverbote), expressando também um postulado

34 TINDALE, Christopher W. Fallacies and Argument Appraisal. Cambridge: Cambridge University Press, 2007, p. 19. 
ERICKSEN, Lauro. Representatividade sindical dos domésticos e os limites das negociações coletivas. Revista Eletrônica Direito e Política, Programa de Pós-Graduação Stricto Sensu em Ciência Jurídica da UNIVALI, Itajaí, v.13, n.2, 20 quadrimestre de 2018. Disponível em: www.univali.br/direitoepolitica - ISSN 1980-7791

de proteção (Schutzgebote) podendo também serem traduzidos como proibições de proteção insuficiente ou imperativos de tutela (Untermaßverbote).

Aplicando tais assertivas teóricas ao objeto de estudo em apreço, há de se ter a noção que a proibição do excesso, na hermenêutica constitucional aplicável ao caso, coaduna-se, perfeitamente, com os postulados de proteção ou os imperativos de tutela postos em relevo. A confluência para com o primeiro tópico se dá na necessidade de se proteger, semelhantemente, tanto o direito fundamental de organização sindical dos empregadores, bem como também a viabilidade de tal organização (algo faticamente inalcançável), quanto os direitos associativos dos domésticos (os quais hão de permanecer protegidos), de modo que se afigura imperativo que as normas de direito privado sejam interpretadas em conformidade com as normas constitucionais que os consagram ${ }^{35}$. Destarte, é imperioso que os elementos fáticos da necessidade prática de se interpretar essa problemática sejam postos em relevo para que se possa vislumbrar, efetivamente, os limites constitucionais da aplicabilidade da inovação trazida pela comentada emenda.

Pode-se compreender, dentro dos limites teóricos analisados por Brigitta Lurger $^{36}$, que a possibilidade de sindicalização dos empregados domésticos já vem a assegurar um nível mínimo de proteção para casos extremos de violações autônomas privadas de direitos fundamentais, ou seja, há o resguardo do direito fundamental de associação para a classe obreira, esse valor já está protegido e tutelado. O excesso provém da imposição da sindicalização dos empregadores, para que participem das convenções e acordos coletivos, daí a necessidade de um imperativo de tutela (Untermaßverbote) que já é prevalente e suficiente para reger as relações entre os particulares envolvidos. Há de se ter em conta, como bem pondera Manfred Klußmann ${ }^{37}$, que os limites da proibição de excesso só

35 PEREIRA, Jane Reis Gonçalves. Apontamentos sobre a Aplicação das Normas de Direito Fundamental nas Relações Jurídicas entre Particulares. In: BARROSO, Luis Roberto (Org.). A Nova Interpretação Constitucional: Ponderação, Direitos Fundamentais e Relações Privadas. $2^{a}$ ed. Rio de Janeiro: Renovar, 2006, p. 469.

36 LURGER, Brigitta. Grundfragen der Vereinheitlichung des Vertragsrechts in der Europaischen Union. Wien: Springer, 2002, p. 321.

37 KLUBMANN, Manfred. Zulässigkeit und Grenzen von nachträglichen Eingriffen des Gesetzgebers in laufende Verträge. Berlin: Duncker und Humblot, 1970, p. 135. 
ERICKSEN, Lauro. Representatividade sindical dos domésticos e os limites das negociações coletivas. Revista Eletrônica Direito e Política, Programa de Pós-Graduação Stricto Sensu em Ciência Jurídica da UNIVALI, Itajaí, v.13, n.2, 20 quadrimestre de 2018. Disponível em: www.univali.br/direitoepolitica - ISSN 1980-7791

podem ser mensurados a partir de um caso em concreto, por isso que a delimitação do caráter contraditório entre a PEC 66/2012 (nova redação do inciso XXVI do artigo 70, da CR/1988) e o direito fundamental de associação (incisos XVII e XXI do artigo 50, da CR/1988), por mais que já existissem sindicatos da categoria profissional antes da promulgação da mencionada emenda, só veio a tomar corpo constitucional a partir da prevalência normativa da alteração analisada (ou seja, a partir de sua concreta existência no plano jurídico).

Isso se dá porque a própria razoabilidade da tutela (ou do interesse a ser alvo desta tutela) é imperativa dentro da questão da proibição do excesso ${ }^{38}$, de modo que, o excesso é tolhido para que haja o mínimo de equidade no tratamento das partes envolvidas no dissenso jurídico. A própria razoabilidade contida na proibição do excesso possui sua origem no princípio da proporcionalidade, uma "regra decisória" prevalente na hermenêutica constitucional ${ }^{39}$. Deste modo, é proporcional e razoável que ocorram limitações na aplicação de direitos e garantias fundamentais entre particulares de normas oriundas do próprio seio constitucional. Tal como se afigura proposto para o caso em tela, com espeque na razoabilidade interpretativa dos preceitos constitucionais vigentes, a proibição do excesso depende da extensão de sua validade e fica adstrita à interpretação de cada norma, segundo o conteúdo e as barreiras que devem ser medidos tais pressupostos limitativos ${ }^{40}$. Deste modo, há de se entender que a existência do sindicato da categoria profissional já atende ao direito fundamental dos empregados domésticos de se reunirem e se associarem livremente, o que não dá azo constitucional para que o princípio do paralelismo simétrico entre as partes (fundamentado faticamente) possa ser vilipendiado como propõe a EC 72.

Percebe-se, portanto, a necessidade de se analisar a luz das premissas constitucionais vigentes, os limites da representação sindical a serem impostos

38 DAVILLA, Sofia. Die Eigenverantwortung im Sgb III Und Sgb II: Obliegenheiten und Sanktionen zur Beendigung von Arbeitslosigkeit und Hilfebedürftigkeit. Franfurt am Main: Peter Lang, 2011, p. 115.

39 MENDES, Gilmar Ferreira; COELHO, Inocêncio Mártires; BRANCO, Paulo Gustavo Gonet. Curso de Direito Constitucional. 2. ed. São Paulo: Saraiva, 2009, p. 330.

40 SCHMIDT, Thomas. Die Freiheit verfassungswidriger Parteien und Vereinigungen: Zur Schrankenlehre im Rahmen von Art. 21 Abs. 2 u 9 Abs. 2 GG. Berlin: Duncker und Humblot, 2003, p. 170. 
ERICKSEN, Lauro. Representatividade sindical dos domésticos e os limites das negociações coletivas. Revista Eletrônica Direito e Política, Programa de Pós-Graduação Stricto Sensu em Ciência Jurídica da UNIVALI, Itajaí, v.13, n.2, 20 quadrimestre de 2018. Disponível em: www.univali.br/direitoepolitica - ISSN 1980-7791

sobre a atividade exercida pelos empregados domésticos, sendo possível, ao final de tal jornada, concluir se a alteração constitucional se coaduna com o direcionamento constitucional estabelecido na carta máxima como viável para o plano político hodierno do Estado Democrático de Direito brasileiro.

\section{CONSIDERAÇÕES FINAIS}

O problema levantado na presente análise não diz respeito aos sindicatos da classe obreira, e, sim, o direcionamento constitucional de se garantir a viabilidade das negociações e dos acordos coletivos a virem a ser por eles realizados (uma questão de paralelismo simétrico, uma decorrência do princípio da igualdade dos entes coletivos laborais). Tal problemática se insere na obrigatoriedade da representação legal dos empregadores, sendo, portanto, necessário, repensar o alcance desta alteração constitucional, a qual, ao invés de fortalecer direitos básicos das empregadas e dos empregados domésticos, virá a trazer uma complicação coletivizada em termos de aplicabilidade prática de seus direitos.

Deste modo, é importante colocar que não é apenas possível, e, sim, imprescindível pensar os limites dos direitos sociais dos empregados, especialmente, no caso levantado, das empregadas e dos empregados domésticos sem que se force a retomar paradigmas de proteção laboral quando se está a discutir implicações de tais direitos na seara dos direitos coletivos.

O presente artigo ainda possui margens para desenvolver vários tópicos, tais como a implicação da necessidade produtiva dentro do ambiente de trabalho do empregado doméstico, a questão de uma mais bem acurada delimitação das características sociológicas do liame subjetivo entre os empregadores domésticos em termos de associações sindicais, dentre alguns outros questionamentos que tangenciam elementos atinentes à emenda constitucional 72 , e que são bastante caros a elucidação dos problemas por ela trazidos.

No entanto, dentro do contexto do que foi efetivamente abordado, há de se ter em relevo que a mais nova alteração constitucional no contexto do direito coletivo do trabalho veio a trazer mudanças bastante conturbadas para esse 
ERICKSEN, Lauro. Representatividade sindical dos domésticos e os limites das negociações coletivas. Revista Eletrônica Direito e Política, Programa de Pós-Graduação Stricto Sensu em Ciência Jurídica da UNIVALI, Itajaí, v.13, n.2, $2^{\circ}$ quadrimestre de 2018. Disponível em: www.univali.br/direitoepolitica - ISSN 1980-7791

ramo jurídico, implementando dificuldades (por enquanto, ainda teóricas) acerca da satisfação de alguns direitos fundamentais das empregadas e dos empregados domésticos. Desse modo, o implemento do reconhecimento das negociações coletivas de tal categoria após a emenda constitucional no 72 deve ser algo visto com muita cautela e várias reservas, dada a viabilidade fática de tal reconhecimento constitucional, uma vez que as suas implicações são deveras incisivas na seara do direito coletivo do trabalho.

Ainda que o tema seja relativamente novo, e não haja nenhuma situação semelhante a ser observada no cenário jurídico nacional anteriormente, que venha a servir de paradigma de como a questão deva (ou ao menos, vislumbrese) ser tratada, é imperioso fazer uma última consideração final no que tange a Lei Complementar no 150 de 01/06/2015 (doravante LC no 150). O problema em tela é a redação do artigo 45 , que trata da contribuição sindical de empregados e empregadores é tão lacônica quanto o máximo que ela poderia ser. 0 mencionado artigo apenas indica que a legislação do capítulo III, título $V$ da CLT (que trata justamente das contribuições sindicais) são aplicáveis às empregadas e aos empregados domésticos, tal como eles estão a ser disciplinados pela novel Legislação.

Dessa feita, sofre-se, mais uma vez, do grande problema da mera repetição legislativa sem que haja uma regulamentação efetiva sobre o tema. Não se está, por ora, a pugnar por uma maior intervenção estatal sobre as relações privadas, longe disso, o que se está a discutir, e, efetivamente, criticar de modo incisivo, é que um dispositivo normativo exarado pelo Senado Federal que tem como indicativo precípuo de ser a própria regulamentação de um dispositivo constitucional atinente a uma emenda que atinge especificamente os trabalhadores domésticos finda apenas por repetir um diploma legal existente há algumas décadas, e que, certamente, não trata das vicissitudes e particularidades que envolvem o trabalho doméstico tal como já explicitado em trechos anteriores desse mesmo trabalho. Assim, a mera repetição do texto trabalhista em vigor não traz nenhuma luz sobre o tema, não que fosse necessária uma inovação legislativa a esse respeito, no entanto, nenhum mecanismo ou mesmo nenhuma forma de interação entre a forma de o 
ERICKSEN, Lauro. Representatividade sindical dos domésticos e os limites das negociações coletivas. Revista Eletrônica Direito e Política, Programa de Pós-Graduação Stricto Sensu em Ciência Jurídica da UNIVALI, Itajaí, v.13, n.2, 20 quadrimestre de 2018. Disponível em: www.univali.br/direitoepolitica - ISSN 1980-7791

empregador contribuir e a maneira do sindicato dos empregadores atuarem foi significativamente proposta pela LC no 150 supramencionada.

Como mencionado, não há nenhuma experiência prévia no cenário juslaboral brasileiro que sirva de guia ou de norteamento para o caso da cobrança e da efetiva atuação dos sindicatos dos empregadores domésticos, principalmente, porque não há nenhuma outra categoria profissional que seja formada única e exclusivamente por pessoas naturais (pessoas físicas). Outro ponto salutar, exposto na LC no 150, que embora não trate da questão sindical, mas que é sensível à particularidade do trabalho doméstico, pretende instituir um SIMPLES para arrecadação e recolhimentos previdenciários e tributários da categoria. Com base nessa particularização, seria no mínimo de se cogitar que a questão sindical sofresse um tratamento igualmente diferenciado na sua proposta efetiva de atuação, no entanto, repise-se, o artigo 45 foi simplesmente lacônico e nada elucidativo em suas disposições normativos, tal como se uma mirrada remissão legal à CLT fosse suficiente para resolver os desígnios de toda uma categoria profissional diferenciada em sua essência de todas as outras por acaso existentes até então.

Conclui-se, derradeiramente, que tanto a Emenda Constitucional prevalente (a EC 72) e a Lei Complementar que a regulamenta no cenário normativo nacional (LC no 150) sofrem do mesmo caráter lacônico e pouco prático, de modo que a sua problemática congênita (tal como discorrido em todo o desenvolvimento do presente artigo) sequer foi amenizada pela sua abjeta regulamentação proposta pelo Senado Federal, sofrendo um total descaso por parte dos órgãos legislativos nacionais, que criam um instituto sem viabilidade prática alguma no cenário laboral atual. 
ERICKSEN, Lauro. Representatividade sindical dos domésticos e os limites das negociações coletivas. Revista Eletrônica Direito e Política, Programa de Pós-Graduação Stricto Sensu em Ciência Jurídica da UNIVALI, Itajaí, v.13, n.2, $2^{\circ}$ quadrimestre de 2018. Disponível em: www.univali.br/direitoepolitica - ISSN 1980-7791

\section{REFERÊNCIA DAS FONTES CITADAS}

BARASSI, Ludovico. II Diritto del Lavoro. Milano: Giuffré, 1949.

BARROSO, Fábio Túlio. Direito Coletivo do Trabalho. São Paulo: LTr, 2010.

BATALHA, Wilson de Souza Campos. Sindicatos, Sindicalismo. 2. ed. São Paulo: LTr, 1994.

BRASIL. Consolidação das Leis do Trabalho (Decreto-Lei no 5.452, de $1^{\circ}$ de maio de 1943). Disponível em: <www.presidencia.gov.br/legislacao>. Acesso em 08 de abril de 2013.

Constituição da República Federativa do Brasil. Disponível em: <www.presidencia.gov.br/legislacao>. Acesso em 08 de abril de 2013.

Lei no 5.859 de 11 de dezembro de 1972 (Lei do Empregado

Doméstico). Disponível em: <www.presidencia.gov.br/legislacao>. Acesso em 08 de abril de 2013.

. Projeto de Lei do Senado no 224/2013, versão final. <http://www.senado.gov.br/atividade/materia/getPDF.asp?t=129645\&tp $=1>$. Acesso em 25 de maio de 2015.

CANARIS, Claus-Wilhelm. Grundrechte und Privatrecht: Eine Zwischenbilanz; stark erweiterte Fassung des Vortrags Gehalten vor Juristischen Gesellschaft. Berlin: De Gruyter, 1999.

CASSAR, Vólia Bonfim. Direito do Trabalho. 7. ed. São Paulo: Método, 2012.

CATARINO, José Martins. Tratado Elementar de Direito Sindical. São Paulo: LTr, 1977.

CESARINO JÚNIOR, Antônio Ferreira. Direito Social. São Paulo, LTr, 1980.

CHIARELLI, Carlos Alberto. O Trabalho e o Sindicato: Evoluções e Desafio. São Paulo, LTr, 2005.

Trabalho na Constituição. São Paulo: LTr, 1990.

COSTA, Orlando Teixeira da. Direito Coletivo do Trabalho e Crise Econômica. São Paulo. LTr, 1991.

DAVILLA, Sofia. Die Eigenverantwortung im Sgb III Und Sgb II: Obliegenheiten und Sanktionen zur Beendigung von Arbeitslosigkeit und Hilfebedürftigkeit. Franfurt am Main: Peter Lang, 2011.

FISCHER, Douglas. Execução de Pena na Pendência de Recursos Extraordinário e Especial em Face da Interpretação Sistêmica da Constituição. Uma Análise do 
ERICKSEN, Lauro. Representatividade sindical dos domésticos e os limites das negociações coletivas. Revista Eletrônica Direito e Política, Programa de Pós-Graduação Stricto Sensu em Ciência Jurídica da UNIVALI, Itajaí, v.13, n.2, $2^{\circ}$ quadrimestre de 2018. Disponível em: www.univali.br/direitoepolitica - ISSN 1980-7791

Princípio da Proporcionalidade: entre a Proibição de Excesso e a Proibição de Proteção Deficiente. Revista Direito Público, v. 6, n. 25, 2009. pp.7-30.

FREEMAN, Richard B.; MEDOFF, L. James. What do Unions Do? New York: Basic Books, 1984.

GIUGNI, Gino. Diritto Sindacale. Bari: Cacucci, 2010.

HINZ, Henrique Macedo. Direito Coletivo do Trabalho. São Paulo: Saraiva, 2012.

KLUßMANN, Manfred. Zulässigkeit und Grenzen von nachträglichen Eingriffen des Gesetzgebers in laufende Verträge. Berlin: Duncker und Humblot, 1970.

LURGER, Brigitta. Grundfragen der Vereinheitlichung des Vertragsrechts in der Europaīschen Union. Wien: Springer, 2002.

MELLO, Marcílio Barenco Corrêa de. O Princípio da Proibição do Excesso na Concessão de Medidas Cautelares pelas Cortes de Contas. Revista do TCEMG, v. 84, n. 3, 2012. pp. 59-80.

MENDES, Gilmar Ferreira; COELHO, Inocêncio Mártires; BRANCO, Paulo Gustavo Gonet. Curso de Direito Constitucional. 2. ed. São Paulo: Saraiva, 2009.

NASCIMENTO, Amauri Mascaro. Curso de Direito do Trabalho: História e Teoria Geral do Direito do Trabalho/Relações Individuais e Coletivas do Trabalho. 25. ed. São Paulo: Saraiva, 2010.

Direito Sindical. 2. ed. São Paulo: Saraiva, 2001.

NORMANDO, Cláudia Cavalcante. Trabalho Doméstico: Valores Jurídicos e Dignidade Humana. São Paulo: Sérgio Antonio Fabris, 2005.

PAMPLONA FILHO, Rodolfo; VILLATORE, Marco Antônio César. Direito do Trabalho Doméstico. 3. ed. São Paulo, LTr, 2006.

RODRIGUEZ, Américo Plá. Princípios de Direito do Trabalho. 3. ed. Tradução de Wagner D. Giglio. São Paulo: LTr, 2000.

PEREIRA, Jane Reis Gonçalves. Apontamentos sobre a Aplicação das Normas de Direito Fundamental nas Relações Jurídicas entre Particulares. In: BARROSO, Luis Roberto (Org.). A Nova Interpretação Constitucional: Ponderação, Direitos Fundamentais e Relações Privadas. 2a ed. Rio de Janeiro: Renovar, 2006.

PINTO, José Augusto Rodrigues. Direito Sindical e Coletivo do Trabalho. 2. ed. São Paulo: LTr, 2002.

RUSSOMANO, Mozart Victor. Princípios Gerais de Direito Sindical. 2. ed., Rio de Janeiro: Forense, 1995. 
ERICKSEN, Lauro. Representatividade sindical dos domésticos e os limites das negociações coletivas. Revista Eletrônica Direito e Política, Programa de Pós-Graduação Stricto Sensu em Ciência Jurídica da UNIVALI, Itajaí, v.13, n.2, $2^{\circ}$ quadrimestre de 2018. Disponível em: www.univali.br/direitoepolitica - ISSN 1980-7791

SCHMIDT, Thomas. Die Freiheit verfassungswidriger Parteien und Vereinigungen: Zur Schrankenlehre im Rahmen von Art. 21 Abs. 2 u 9 Abs. 2 GG. Berlin: Duncker und Humblot, 2003.

SÜßEKIND, Arnaldo Lopes. Direito Constitucional do Trabalho. 3. ed. São Paulo: Renovar, 2004.

TINDALE, Christopher W. Fallacies and Argument Appraisal. Cambridge: Cambridge University Press, 2007.

VIANNA, José de Segadas. Direito Coletivo do Trabalho. 2. ed. São Paulo: LTr, 1972.

Recebido em: 15/08/2018

Aprovado em: 19/06/2018 